\title{
Effects of Estradiol on Cocaine Self-Administration and Cocaine Discrimination by Female Rhesus Monkeys
}

\author{
Nancy K Mello*,', S Stevens Negus', Inge M Knudson', Maureen Kelly' and Jack H Mendelson' \\ 'Department of Psychiatry, Alcohol and Drug Abuse Research Center, Harvard Medical School_McLean Hospital, Belmont, MA, USA
}

\begin{abstract}
The ovarian steroid hormone, estradiol, enhances the reinforcing and locomotor activating effects of cocaine in rodents under some conditions. The present study evaluated the acute effects of estradiol benzoate $\left(E_{2} \beta\right)$ on cocaine self-administration and cocaine discrimination in female rhesus monkeys. Cocaine self-administration $(0.10 \mathrm{mg} / \mathrm{kg} / \mathrm{inj}$., i.v.) was maintained on a fixed-ratio (FR) 30 schedule of reinforcement, and monkeys had access to cocaine during one 2-h session each day. $\mathrm{E}_{2} \beta$ in a cyclodextrin vehicle (0.0000 I$0.01 \mathrm{mg} / \mathrm{kg}$, i.m.) was administered $30 \mathrm{~min}$ before test sessions conducted twice each week. Cocaine doses were administered in an irregular order during each dose-effect curve determination $(0.00 \mathrm{I}-0.3 \mathrm{mg} / \mathrm{kg} / \mathrm{inj}$.). Blood samples were collected after test sessions to determine $17 \beta$-estradiol levels. Banana-flavored food pellets were available on an FR 30 schedule in three I-h sessions each day. Five monkeys were trained to discriminate cocaine $(0.18 \mathrm{mg} / \mathrm{kg}$, i.m.) from saline in a two-key food-reinforced procedure, and the effects of pretreatment with $\mathrm{E}_{2} \beta$ in cyclodextrin and in sesame oil were studied. Acute administration of $\mathrm{E}_{2} \beta$ did not consistently alter the cocaine self-administration or drug discrimination dose-effect curves in comparison to saline control treatment. Females also did not selfadminister $E_{2} \beta\left(0.0000 \mathrm{I}-0.10 \mathrm{mg} / \mathrm{kg}\right.$, i.v.) above saline levels. Finally, $E_{2} \beta(0.000 \mathrm{I}-0.0 \mathrm{l} \mathrm{mg} / \mathrm{kg}$, i.m.) did not substitute for cocaine in monkeys trained to discriminate cocaine from saline. Taken together, these data suggest that over the dose range studied, estradiol administration does not consistently alter the abuse-related effects of cocaine in female rhesus monkeys.

Neuropsychopharmacology (2008) 33, 783-795; doi:I0.1038/sj.npp. I30 I45 I; published online I6 May 2007
\end{abstract}

Keywords: cocaine; estradiol; cocaine self-administration; non-human primate; cocaine discrimination; DHEA

\section{INTRODUCTION}

Several lines of evidence suggest that the interactions between the ovarian steroid hormone estradiol and cocaine may influence cocaine's abuse-related effects. Cocaine stimulates release of estradiol in female monkeys during the follicular phase of the menstrual cycle (Mello et al, 2000). Significant increases in plasma estradiol levels occurred within $16 \mathrm{~min}$ after intravenous (i.v.) cocaine administration, and estradiol remained significantly above baseline levels for $14 \mathrm{~min}$ (Mello et al, 2004a). This relatively rapid time course is consistent with evidence that estradiol has non-genomic effects that may precede its traditional genomic steroid actions and influence behavior as well as neuroendocrine and reproductive function (Falkenstein et al, 2000; Moore and Evans, 1999; Vasudevan and Pfaff, 2007; Wong et al, 1996). Both estradiol and cocaine increase extracellular dopamine levels measured in microdialysis studies in rodents (Becker, 1999; Becker et al, 2001; Di

\footnotetext{
* Correspondence: Dr NK Mello, Alcohol and Drug Abuse Research Center, Harvard Medical School-McLean Hospital, II 5 Mill Street, Belmont, MA 02478, USA, Tel: + I 617855 2746, Fax: + | 617855 2519, E-mail: mello@mclean.harvard.edu

Received 28 December 2006; revised 23 March 2007; accepted II April 2007
}

Chiara, 1995; Hemby et al, 1997), and dopamine is generally thought to subserve the reinforcing effects of cocaine (Kuhar et al, 1991; Woolverton and Johnson, 1992). The extent to which cocaine-induced increases in estradiol levels may contribute to cocaine-related increases in extracellular dopamine in the nucleus accumbens and ventral striatum is unknown.

Estradiol enhances both the reinforcing and the locomotor-activating effects of cocaine in rodents under a number of conditions (for review see Carroll et al, 2004; Festa and Quinones-Jenab, 2004; Lynch et al, 2002; Mello and Mendelson, 2002). In cocaine self-administration studies, progressive ratio break points for cocaine were significantly higher at estrus than at other phases of the estrous cycle (Hecht et al, 1999; Roberts et al, 1989). Female rats also selected significantly higher doses of cocaine during estrus than at metestrus/diestrus (Lynch et al, 2002). There are many differences between the 4- to 5-day estrous cycle in rats and the 28-day menstrual cycle in women and nonhuman primates, so direct comparisons are difficult. However, the proestrus phase of the estrous cycle, when estradiol and progesterone levels are increasing, corresponds to the periovulatory phase of the menstrual cycle (Becker et al, 2002; Freeman, 1994; Lynch et al, 2002). Ovulation defines the beginning of the estrus phase of the estrous cycle, and in the non-fertile cycle, estradiol and 
progesterone levels decrease after ovulation. The relatively low levels of estradiol and progesterone during late estrus and diestrus I in the estrous cycle are similar to hormonal levels during the follicular phase of the menstrual cycle.

Ovariectomized rats given estradiol met acquisition criteria for cocaine self-administration more readily, and took more cocaine than ovariectomized rats without estradiol replacement (Hu et al, 2004; Jackson et al, 2006; Lynch et al, 2001). In gonadally intact rats, an antiestrogen, tamoxifen, reduced the number of rats that met acquisition criteria for cocaine self-administration from 80 to $30 \%$ (Lynch et al, 2001). Taken together, these findings suggest that estradiol levels may be one important modulator of the reinforcing effects of cocaine in rodents. However, there are some exceptions to these general findings. For example, when drug-naïve, gonadally intact and ovariectomized female rats were given access to unit doses of cocaine $(1.0-2.5 \mathrm{mg} / \mathrm{kg} / \mathrm{inj}$.) that maintained robust and stable selfadministration, there were no differences in the acquisition of cocaine self-administration (Caine et al, 2004; Grimm and See, 1997). There were also no differences in the acquisition of cocaine self-administration $(1.5 \mathrm{mg} / \mathrm{kg} / \mathrm{inj}$.) between ovariectomized females with and without estradiol replacement (Lynch and Taylor, 2005). Moreover, there were no differences in the shape and position of the cocaine self-administration dose-effect curve $(0.032-3.2 \mathrm{mg} / \mathrm{kg} / \mathrm{inj}$.) determined in female rats before and after ovariectomy, or in ovariectomized females before and after estradiol replacement (Caine et al, 2004). Similarly, although ovariectomized female rats with estrogen replacement selfadministered significantly more cocaine then ovariectomized females without estrogen replacement at cocaine unit doses of 0.3 and $0.4 \mathrm{mg} / \mathrm{kg} /$ inj., there were no differences in responding for a higher unit dose of $0.5 \mathrm{mg} / \mathrm{kg} / \mathrm{inj}$. cocaine (Hu et al, 2004).

Clinical studies of the subjective effects of cocaine at different phases of the menstrual cycle have been inconsistent. In some studies, no differences in the subjective effects of cocaine were detected (Collins et al, 2007; Lukas et al, 1996; Mendelson et al, 1999; Munro et al, 2006). In other studies, the subjective effects of both cocaine and $d$-amphetamine were reported to be greater during the follicular phase of the menstrual cycle, when estradiol and progesterone levels are low, than during luteal phase, when both estradiol and progesterone levels are high (Evans et al, 2002; Justice and de Wit, 1999; Sofuoglu et al, 1999; White et al, 2002). This difference in subjective responses to cocaine or to $d$-amphetamine as a function of menstrual cycle phase is usually interpreted as reflecting the fact that progesterone acts as an antagonist of estradiol under several conditions (Clark and Mani, 1994; Dierschke et al, 1973; Van Vugt et al, 1992; Wildt et al, 1981). Consistent with this interpretation, administration of progesterone to women during the follicular phase reduced the positive subjective effects of smoked and i.v. cocaine (Evans and Foltin, 2006; Sofuoglu et al, 2002, 2004).

In a clinical study designed to examine the influence of estradiol on subjective responses to $d$-amphetamine, independent of the effects of progesterone, women were studied during the early- and the late follicular phase of the menstrual cycle in an own-control design (Justice and de Wit, 2000a). During the early follicular phase, estradiol levels averaged $57 \mathrm{pg} / \mathrm{ml}$, and during the late follicular phase, estradiol levels averaged $175 \mathrm{pg} / \mathrm{ml}$. Progesterone levels were low at both the early- and late follicular phase of the menstrual cycle and averaged $1.3 \mathrm{ng} / \mathrm{ml}$. Although $d$ amphetamine ( $15 \mathrm{mg}$, p.o.) significantly increased heart rate and positive subjective effects in comparison to placebo, differences in estradiol levels as a function of menstrual cycle phase did not alter the physiologic or subjective effects of $d$-amphetamine (Justice and de Wit, 2000a). To the best of our knowledge, only one clinical study has examined the effects of estradiol administration on the subjective effects of $d$-amphetamine in follicular phase women (Justice and de Wit, 2000b). Two groups of women were given $d$-amphetamine (10 mg, p.o.) or placebo tablets during treatment with either a transdermal estradiol patch or a placebo patch. Estradiol treatment increased plasma estradiol to levels that were approximately 10 times higher than during the normal early follicular phase. Estradiol treatment increased ratings of 'pleasant stimulation' after $d$-amphetamine in comparison to placebo capsules, but other positive subjective effect ratings (euphoria, 'like drug', and 'feel high') were not significantly increased. Interestingly, estradiol alone increased ratings of 'pleasant stimulation' in women given placebo amphetamine (Justice and de Wit, 2000b).

Neuroendocrine control of the menstrual cycle of macaque monkeys is very similar to that of women, and the rhesus monkey has long been a model of choice in reproductive biology (Hotchkiss and Knobil, 1994; Knobil, 1980; Knobil and Hotchkiss, 1988). In endocrine studies in rhesus monkeys, cocaine stimulated estradiol release only during the follicular phase when estradiol was unopposed by progesterone, and not during the luteal phase when progesterone levels were high (Mello et al, 2000). We examined cocaine self-administration during ovulatory menstrual cycles in cynomolgus female monkeys (Mello et al, 2007). There were no consistent changes in progressive ratio break points for reinforcing unit doses of cocaine $(0.01$ and $0.032 \mathrm{mg} / \mathrm{kg} / \mathrm{inj}$.) as a function of menstrual cycle phase, a finding similar to clinical studies described earlier.

This is the first study of the effects of estradiol administration on cocaine's reinforcing and discriminative stimulus effects in female rhesus monkeys. Cocaine selfadministration and drug discrimination dose-effect curves were determined during estradiol and placebo treatment. Females were also given access to i.v. estradiol in drug selfadministration studies to determine if it substituted for cocaine. In drug discrimination studies, estradiol was substituted for cocaine to determine the extent to which it shared discriminative stimulus properties with cocaine. A wide range of $\mathrm{E}_{2} \beta$ doses and cocaine doses were studied in the same females across conditions. To mimic the rapidonset, non-genomic actions of estradiol (Falkenstein et al, 2000; Moore and Evans, 1999; Vasudevan and Pfaff, 2007; Wong et al, 1996), $\mathrm{E}_{2} \beta$ was prepared in a cyclodextrin vehicle. In drug discrimination studies, treatment with $\mathrm{E}_{2} \beta$ in cyclodextrin was compared with treatment with $\mathrm{E}_{2} \beta$ in sesame oil to assess possible differences in the non-genomic and genomic effects of estradiol. To control for the effects of basal levels of plasma estradiol, both ovariectomized females and gonadally intact females were studied. 


\section{MATERIALS AND METHODS}

\section{Subjects}

Studies were conducted in 16 rhesus monkeys (Macaca mulatta). The time course of $17 \beta$-estradiol levels after administration of estradiol benzoate $\left(\mathrm{E}_{2} \beta\right)$ was studied in four gonadally intact female and four gonadally intact male monkeys. Four drug-naïve monkeys were studied in cocaine self-administration procedures. Two monkeys were ovariectomized and two monkeys were gonadally intact. Five monkeys with a history of cocaine self-administration were studied in cocaine discrimination procedures. Female monkeys weighed $4-6 \mathrm{~kg}$ and were maintained on a diet of multiple vitamins, fresh fruit, and Lab Diet Jumbo Monkey biscuits (PMI Feeds Inc., St Louis, MO). Water was continuously available. In cocaine self-administration studies, monkeys also worked at an operant task for $1 \mathrm{~g}$ banana-flavored pellets (Precision Primate Pellets Formula L/I Banana Flavor, PJ Noyes Co., Lancaster, NH) during three daily sessions of food availability (see below). In drug discrimination procedures, each monkey was maintained on a diet of 8-15 monkey biscuits (Purina Monkey Chow Jumbo no. 5037) and one piece of fresh fruit per day. During the week, all food was delivered after the experimental session, whereas on weekends, food was delivered between 0900 hours and noon. A 12-h light-dark cycle was in effect (lights on from 0700 to 1900 hours).

Animal maintenance and research were conducted in accordance with the guidelines provided by the NIH Committee on Laboratory Animal Resources. The facility was licensed by the United States Department of Agriculture, and protocols were approved by the Institutional Animal Care and Use Committee. The health of the monkeys was periodically monitored by consulting veterinarians. Monkeys had visual, auditory, and olfactory contact with other monkeys throughout the study. Operant food and drug self-administration procedures and foraging toys provided opportunities for environmental manipulation and enrichment (Line, 1987). Music or nature videotapes were also played to provide additional environmental enrichment.

\section{Time Course of Estradiol in Cyclodextrin and in Sesame Oil}

Estradiol doses used in the current study were based on a previous study conducted in five ovariectomized females to determine the physiologically relevant dose range of $\mathrm{E}_{2} \beta$ (Mello et al, 2004b). In the present study, we compared the time course of plasma levels of $17 \beta$-estradiol in a $\beta$-cyclodextrin solution and a sesame oil vehicle. $\mathrm{E}_{2} \beta$ in a cyclodextrin solution $(0.0001,0.001$, and $0.01 \mathrm{mg} / \mathrm{kg}$, intramuscular (i.m.)) was administered to four gonadally intact female monkeys. Samples for $17 \beta$-estradiol analyses were collected at $5 \mathrm{~min}$ intervals for $120 \mathrm{~min}$ to determine if plasma estradiol levels remained elevated for the duration of the cocaine self-administration and cocaine discrimination sessions described below. The time course of $\mathrm{E}_{2} \beta$ $(0.01 \mathrm{mg} / \mathrm{kg}$, i.m. $)$ in a sesame oil solution on plasma levels of $17 \beta$-estradiol was determined in four male monkeys. Samples were collected at 5 or $10 \mathrm{~min}$ intervals for $60 \mathrm{~min}$, then at 90, 120, $240 \mathrm{~min}, 24$ and $48 \mathrm{~h}$.

\section{Cocaine Self-Administration Procedures}

Surgical procedures. Surgical implantation of i.v. catheters for cocaine self-administration was performed under aseptic conditions. Anesthesia was maintained with isoflurane (1-2\% in oxygen). A double-lumen silicone rubber catheter (inside diameter 0.028 inch; outside diameter 0.088 inch; Saint Gobain Performance Plastics, Beaverton, MI) was implanted in the internal jugular or femoral vein and exited in the mid-scapular region. After surgery, monkeys were given an antibiotic (Procaine Penicillin G, 300000 U/ $\mathrm{kg} /$ day, i.m.) for 5 days. An analgesic dose of buprenorphine $(0.032 \mathrm{mg} / \mathrm{kg}$, i.m. $)$ was administered twice daily for 3 days after surgery. The i.v. catheter was protected by a tether system that consisted of a custom-fitted nylon vest connected to a flexible stainless steel cable and fluid swivel (Lomir Biomedical, Malone, NY). This flexible tether system permitted monkeys to move freely. Catheter patency was periodically evaluated by i.v. administration of ketamine $(5 \mathrm{mg} / \mathrm{kg})$ or the short-acting barbiturate methohexital $(3 \mathrm{mg} / \mathrm{kg}$ ) through the catheter lumen. The catheter was considered to be patent if i.v. administration of ketamine or methohexital produced a loss of muscle tone within $10 \mathrm{~s}$.

Apparatus and behavioral procedures. Each monkey was individually housed in a well-ventilated stainless steel chamber $(66 \times 76 \times 94 \mathrm{~cm})$ equipped with a custom-designed operant panel $(28 \times 28 \mathrm{~cm})$ mounted on the front wall. The conditions of food ( $1 \mathrm{~g}$ banana-flavored pellet) and cocaine $(0.10 \mathrm{mg} / \mathrm{kg}$, i.v.) availability were associated with different colored stimulus lights projected on the center response key on the operant response panel. During food availability, the response key was red and during cocaine availability, the response key was green. Behavioral sessions were conducted each day, 7 days a week. Schedules of reinforcement and data collection were controlled by microprocessors and software purchased from Med Associates Inc. (Georgia, VT).

Each 2-h cocaine self-administration session was divided into four 20-min response periods, each separated by a 10min time-out period. A priming injection of the unit dose of cocaine or saline available for self-administration occurred at the beginning of each of the four components. A post-injection time-out of $60 \mathrm{~s}$ was in effect. During the post-injection time-outs and time-outs between session components, the response key was yellow.

Training procedures. Monkeys were initially trained to key press for banana-flavored food pellets $(1 \mathrm{~g})$ available on a fixed-ratio (FR) schedule. The response requirement was gradually increased from FR 1 to FR 20 . After delivery of a food pellet, there was a $60 \mathrm{~s}$ time-out period, during which responding had no scheduled consequences. Once foodmaintained responding was stable on an FR 20 schedule, monkeys were implanted with an i.v. catheter as described above, and trained to self-administer cocaine $(0.10 \mathrm{mg} / \mathrm{kg} /$ inj.) on gradually increasing values of an FR schedule. During training, the number of cocaine injections was limited to 20 in each 20-min component of the session, or a total of 80 injections over the 2-h session. In addition to the daily cocaine self-administration session, three 1-h food self-administration sessions were scheduled each day. 
Cocaine sessions began at 1100 hours and food sessions began at 1600,2000 , and 0800 hours. Food was available on an FR 30 schedule of reinforcement, and the number of pellets was limited to 25 in each 1-h session, for a total of 75 pellets per day.

Cocaine and estradiol self-administration dose-effect curve determinations. After cocaine self-administration was stable on an FR 30 schedule, cocaine or saline injections were freely available during test sessions to avoid a ceiling effect. Cocaine availability was alternated with saline for 2 or 3 days or until saline reliably maintained low levels of responding. Subsequently, cocaine dose-effect curves were determined by substituting saline or cocaine $(0.001-0.3 \mathrm{mg} /$ $\mathrm{kg} / \mathrm{inj}$.) for the cocaine-training dose $(0.10 \mathrm{mg} / \mathrm{kg} / \mathrm{inj}$.). A different sequence of cocaine doses was presented to each monkey, and dose-effect curves were determined in the same order for a given monkey under each estradiol treatment condition. Usually two dose-effect curve test sessions were run each week on Tuesdays and Fridays. The same procedure was used to determine if $\mathrm{E}_{2} \beta$ in a cyclodextrin solution $(0.00001-0.1 \mathrm{mg} / \mathrm{kg}$, i.v.) maintained responding leading to its self-administration in the same cocaine-trained monkeys.

$E_{2} \beta$ treatment and blood sample collection. In drug selfadministration studies, after baseline cocaine dose-effect curves were established, single doses of saline or $\mathrm{E}_{2} \beta$ in cyclodextrin $(0.00001-0.01 \mathrm{mg} / \mathrm{kg})$ were administered intramuscularly $30 \mathrm{~min}$ before the cocaine self-administration session began. Blood samples were collected at the end of the test session to determine hormone levels during the cocaine dose-effect curve determinations. Monkeys were briefly anesthetized with a low dose of ketamine $(3 \mathrm{mg} / \mathrm{kg}$, i.m.), and $1.25 \mathrm{ml}$ of blood was collected in a heparinized tube. Samples were centrifuged, and plasma was stored at $70^{\circ} \mathrm{F}$ until analyzed for $17 \beta$-estradiol levels.

\section{Cocaine Discrimination Procedures}

Apparatus. Each monkey was housed individually in a well-ventilated, stainless steel chamber $(56 \times 71 \times 69 \mathrm{~cm})$. The home cages of all monkeys were modified to include an operant panel $(28 \times 28 \mathrm{~cm})$ mounted on the front wall. Three round translucent response keys $(5.1 \mathrm{~cm}$ diameter) were arranged $3.5 \mathrm{~cm}$ apart in a horizontal row $9 \mathrm{~cm}$ from the top of the operant panel. Each key could be transilluminated by red or green stimulus lights (Superbright LED's). In addition, the operant panel supported an externally mounted pellet dispenser (Gerbrands, model G5310, Arlington, MA) that delivered $1 \mathrm{~g}$ fruit-flavored food pellets (Precision Primate Pellets Formula L/I Banana Flavor, PJ Noyes Co., Lancaster, $\mathrm{NH}$ ) to a food receptacle mounted on the cage beneath the operant response panel. Operation of the operant panels and data collection were accomplished with IBM-compatible computers and interface systems (Med Associates, St Albans, VT) located in a separate room.

Cocaine discrimination training. Discrimination training was conducted 5 days per week during daily sessions beginning between 0900 and 1000 hours. Daily sessions were composed of multiple cycles. Each cycle consisted of a 15-min time-out period followed by a 5-min response period. During the time-out, all stimulus lights were off, and responding had no scheduled consequences. During the response period, the right and left response keys were transilluminated red or green, and monkeys could earn up to 10 food pellets by responding under an FR 30 schedule of food presentation. For three monkeys in this study, the left key was illuminated green, and the right key was illuminated red. The colors of the response keys were reversed for the other two monkeys. The center key was not illuminated at any time, and responding on the center key had no scheduled consequences. If all available food pellets were delivered before the end of the 5-min response period, the stimulus lights transilluminating the response keys were turned off, and responding had no scheduled consequences for the remainder of the 5-min period.

On training days, monkeys were given an i.m. injection of either saline or $0.18 \mathrm{mg} / \mathrm{kg}$ cocaine $5 \mathrm{~min}$ after the beginning of each time-out period (ie, $10 \mathrm{~min}$ before the response period). Following the administration of saline, responding on only the green key (the saline-appropriate key) produced food, whereas following administration of $0.18 \mathrm{mg} / \mathrm{kg}$ cocaine, only responding on the red key (the drugappropriate key) produced food. Responses on the inappropriate key reset the FR requirement on the appropriate key. Sessions consisted of 1-5 cycles, and if the training dose of cocaine was administered, it was administered only during the last cycle. Thus, training days consisted of $0-5$ saline cycles followed by $0-1$ drug cycles.

During each response period, three dependent variables were determined using the following equations.

(1) Percent injection-appropriate responding before delivery of the first reinforcer:

Injection-appropriate responses emitted before 1st reinforcer

Total responses emitted before delivery of 1st reinforcer

(2) Percent injection-appropriate responding for the entire response period:

$\underline{\text { Injection-appropriate responses emitted during response period }} \times 100$ Total responses emitted during response period

(3) Response rate:

Total responses emitted during response period

Total time response keys transilluminated

Monkeys were considered to have acquired cocaine discrimination when the following three criteria were met for seven of eight consecutive training sessions: (1) the percent injection-appropriate responding before delivery of the first reinforcer was greater than or equal to $80 \%$ for all cycles; (2) the percent injection-appropriate responding for the entire cycle was greater than or equal to $90 \%$ for all cycles; (3) response rates during saline training cycles were greater than 0.5 responses/s.

Discrimination testing. Once monkeys met criterion levels of cocaine discrimination, testing began. Test sessions were identical to training sessions except that (1) responding on either key produced food, and (2) test compounds were studied using either a substitution protocol or a pretreatment protocol. In the substitution test procedure, test drugs were administered using a cumulative dosing procedure. 
In this procedure, increasing doses of the test drug were administered at the beginning of each successive cycle, instead of saline or the cocaine training dose, and each successive dose increased the total cumulative dose by $0.5 \mathrm{log}$ units. The drugs studied were cocaine $(0.0056-0.56 \mathrm{mg} / \mathrm{kg})$, the monoamine releaser $d$-amphetamine $(0.0056-0.56 \mathrm{mg} /$ $\mathrm{kg}$ ), the kappa opioid receptor agonist U69,593 (0.00056$0.018 \mathrm{mg} / \mathrm{kg}$ ), and estradiol in cyclodextrin $(0.0001-0.01 \mathrm{mg} /$ $\mathrm{kg}$ ). Dose-effect curves for each drug were determined twice with overlapping dose ranges offset by $0.25 \mathrm{log}$ units. For example, cocaine was studied first using the doses of 0.0056 , $0.018,0.056,0.18$, and $0.56 \mathrm{mg} / \mathrm{kg}$ and second using doses of $0.01,0.032,0.1$, and $0.32 \mathrm{mg} / \mathrm{kg}$. A drug was considered to substitute for cocaine if it produced a dose-dependent increase in cocaine-appropriate responding and a maximum of $\geqslant 90 \%$ cocaine-appropriate responding.

In the pretreatment test procedure, vehicle or estradiol (0.0001-0.01 mg/kg, i.m.) was administered as a pretreatment to determination of a cumulative cocaine discrimination dose-effect curve $(0.0056-0.56 \mathrm{mg} / \mathrm{kg}$ in $0.5 \mathrm{log}$ unit increments). Two approaches were used to examine the effects of estradiol on cocaine discrimination. In the first approach, estradiol in a cyclodextrin vehicle was administered 15 min before determination of a cocaine dose-effect curve. The second approach was designed to assess the slower-onset, longer-acting effects that might be produced by estradiol suspended in sesame oil. A 3-day procedure was used. On day 0 , animals underwent a training session. If criterion levels of performance were observed, then a single dose of sesame oil vehicle or estradiol was administered within $1 \mathrm{~h}$ after the session. On day 1 , approximately $22 \mathrm{~h}$ after vehicle/hormone treatment, a cumulative cocaine dose-effect curve was determined. A second dose of the vehicle/hormone (identical to the treatment administered on day 0) was then administered on day 1 after the test session. On Day 2, approximately $22 \mathrm{~h}$ after the second treatment, another cumulative cocaine dose-effect curve was determined. A control cocaine dose-effect curve was determined before each test with vehicle or hormone treatment, and results during the test were compared to the control dose-effect curve determined before the test.

The order in which studies were conducted and the numbers of monkeys participating in each type of study were (1) substitution studies $(N=3)$, (2) pretreatment studies with estradiol in cyclodextrin vehicle $(N=3)$, and (3) pretreatment studies with estradiol in sesame oil vehicle $(N=4)$. In general, all substitution and pretreatment studies with hormone in cyclodextrin vehicle were conducted on Tuesdays and Fridays, and training sessions were conducted on Mondays, Wednesdays, and Thursdays. Thus, test sessions were separated by at least 2 days. Pretreatment studies with hormones in sesame oil vehicle were usually conducted on Monday to Wednesday. Training was suspended for at least 2 days (usually Thursday and Friday) after each 3-day test block to prevent disruption in training due to residual hormone effects. Subsequently, training was resumed for at least four training sessions, and a control cocaine dose-effect curve was redetermined (usually Monday to Friday of the following week). If full substitution was observed at the training dose of $0.18 \mathrm{mg} / \mathrm{kg}$, then the next hormone test was conducted. Thus, test sessions with estradiol in sesame oil vehicle were separated by at least
5 days and usually by 12 days. Test sessions were conducted only if the three criteria listed above under 'Criteria for discrimination' were met during the training day immediately preceding the test day. Mean data from saline and drug cycles during the training day immediately preceding the initial test day served as the control data for the subsequent test day. If responding did not meet criterion levels of discrimination performance, then training was continued until criterion levels of performance were obtained for at least 2 consecutive days.

Drug discrimination data analysis. Individual subject graphs of the percent cocaine-appropriate responding (for the entire response period) and the response rate were plotted as a function of the dose of cocaine. Control data from saline and cocaine training cycles are also included for comparison. Discrimination $\mathrm{ED}_{50}$ values were defined as the dose of drug that produced 50\% cocaine-appropriate responding, and $\log \mathrm{ED}_{50}$ values were calculated by log-linear regression in all monkeys, in which the drug dose-dependently produced $\geqslant 50 \%$ cocaine-appropriate responding. Log $\mathrm{ED}_{50}$ values were than averaged to yield mean values and $95 \%$ confidence limits $(\mathrm{CL})$. Mean $\mathrm{ED}_{50}$ values and $95 \%$ CL were converted to linear values for presentation in the tables. In substitution studies, a test drug was considered to substitute for cocaine if it produced a dose-dependent increase in cocaine-appropriate responding and a minimum of $\geqslant 90 \%$ cocaine-appropriate responding. In pretreatment studies, a drug was considered to alter the cocaine discrimination dose-effect curve if the 95\% CL of the $\mathrm{ED}_{50}$ for the control cocaine dose-effect curve did not overlap with the $95 \% \mathrm{CL}$ of the $\mathrm{ED}_{50}$ for the test cocaine dose-effect curve.

Drugs. Cocaine $\mathrm{HCl}$ was obtained from the National Institute on Drug Abuse (NIH, Bethesda, MD) and was dissolved in sterile saline. $\mathrm{E}_{2} \beta$ was purchased from Sigma Chemical Co. (St Louis, MO) and was dissolved in cyclodextrin (Wacker Chemie AG, Munich, Germany) or in sesame oil (Sigma Chemical Co.). $d$-Amphetamine sulfate and U69,593 were purchased from Sigma Chemical Co. and were dissolved in sterile water from Sigma Chemical Co. All drug solutions were filter-sterilized using a $0.22 \mu \mathrm{m}$ Millipore filter and stored in pyrogen-free vials. Doses were calculated using the salt forms of the drugs given above.

\section{Estradiol Assay Procedures}

Plasma concentrations of $17 \beta$-estradiol (E2) were determined in duplicate using a direct, double-antibody radioimmunoassay (MP Biomedicals, LLC, Solon, $\mathrm{OH}$ ). The protocol was modified as follows: the plasma samples were extracted, and then reconstituted in zero standard. The assay sensitivity was $4.1 \mathrm{pg} / \mathrm{ml}$ and the intra- and inter-assay confidence intervals were 10.8 and $11.9 \%$, respectively.

\section{RESULTS}

\section{Plasma Estradiol Levels after $\mathrm{E}_{2} \beta$}

Plasma levels of $17 \beta$-estradiol after $\mathrm{E}_{2} \beta$ administration were compared to control levels with Dunnett's post-test, after 
log transforming the data. Figure 1 shows that peak levels of $17 \beta$-estradiol in cyclodextrin were detected within 20-25 min after i.m. administration. The lowest dose of $\mathrm{E}_{2} \beta \quad(0.0001 \mathrm{mg} / \mathrm{kg})$ increased $17 \beta$-estradiol significantly above baseline only at 35,55 , and 60 min after injection $(P<0.05)$. Moderate doses of 0.001 and $0.01 \mathrm{mg} / \mathrm{kg}$, $\mathrm{E}_{2} \beta$ increased $17 \beta$-estradiol significantly above baseline at all time points $(P<0.01)$. Importantly, $17 \beta$-estradiol levels remained elevated for $120 \mathrm{~min}$, the length of the cocaine self-administration and cocaine discrimination sessions. Plasma levels of $17 \beta$-estradiol in a sesame oil solution increased very slowly and reached peak levels within $240 \mathrm{~min}$. After administration of $\mathrm{E}_{2} \beta$, $17 \beta$-estradiol levels remained elevated at $24 \mathrm{~h}$ after administration.

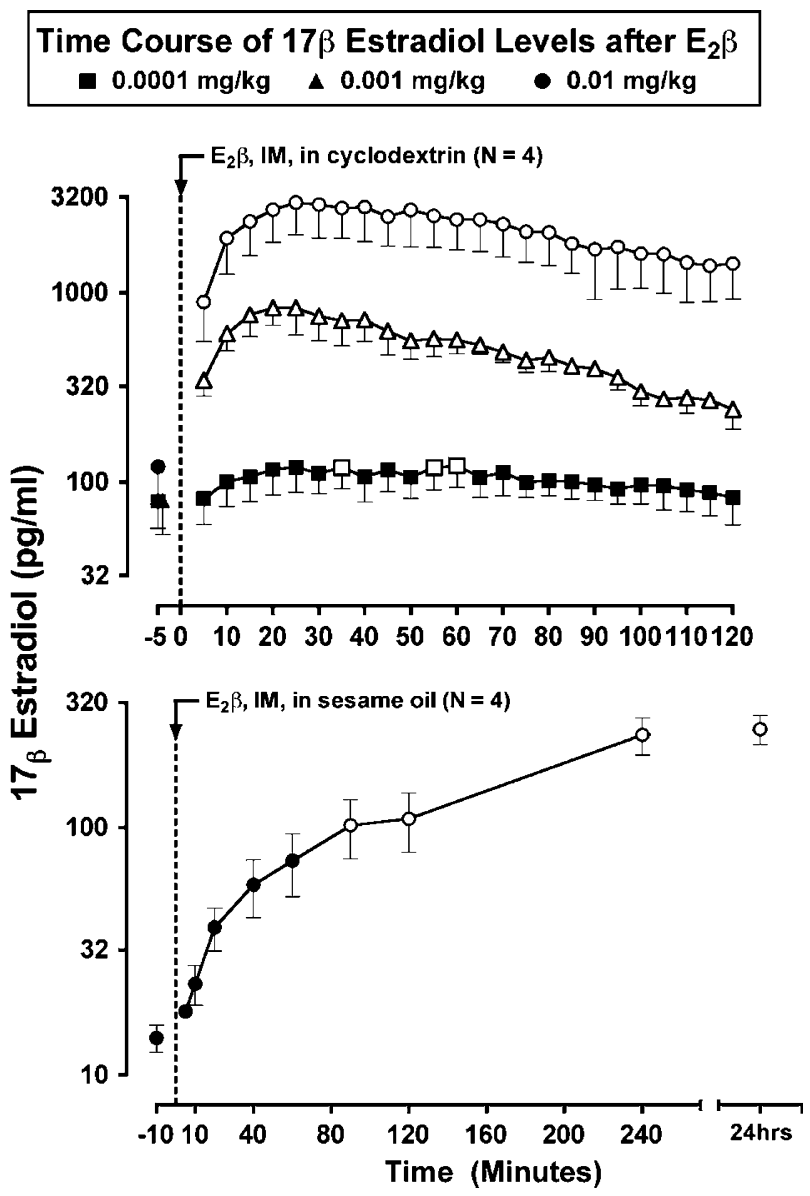

Figure I Time course of plasma levels of $17 \beta$-estradiol after i.m injection of $E_{2} \beta$ in $\beta$-cyclodextrin or sesame oil. The top panel shows the time course of $17 \beta$-estradiol after administration of $0.000 \mathrm{I} \mathrm{mg} / \mathrm{kg}$ (squares), $0.001 \mathrm{mg} / \mathrm{kg}$ (triangles), or $0.01 \mathrm{mg} / \mathrm{kg}$ (circles) $\mathrm{E}_{2} \beta$ in a cyclodextrin solution. The bottom panel shows the time course of $17 \beta$-estradiol after administration of $E_{2} \beta$ in a sesame oil solution. Abscissae: time after injection. Ordinates: plasma levels of $17 \beta$-estradiol (logarithmic scale). One-way ANOVA for repeated measures indicated a significant main effect of estradiol injection on plasma $17 \beta$-estradiol levels at the two highest doses of $\mathrm{E}_{2} \beta$ in cyclodextrin $(P<0.000 \mathrm{I}, \mathrm{F}=11.98$ and 22.56 at the $0.00 \mathrm{I}$ and $0.0 \mathrm{I}$ doses, respectively) and in sesame oil $(P<0.000 \mathrm{I}$, $\mathrm{F}=20$ ). Open symbols represent time points at which the $17 \beta$-estradiol level was significantly higher than baseline (Dunnett's post-test, $P<0.01-0.05$ ).

\section{Cocaine Self-Administration Dose-Effect Curves}

The effects of $\mathrm{E}_{2} \beta$ on cocaine self-administration doseeffect curves in individual monkeys are shown in Figures 2, 3 , 4, and 5. During saline control treatment, a unit dose of $0.01 \mathrm{mg} / \mathrm{kg}$ cocaine was at the peak of the dose-effect curve in three monkeys. In monkey Rh-93B061, estradiol doses of $0.00001,0.001$, and $0.01 \mathrm{mg} / \mathrm{kg}$, i.m., tended to increase responding for $0.003 \mathrm{mg} / \mathrm{kg} / \mathrm{inj}$. cocaine and shift the peak of the cocaine dose-effect curve to the left. However, these effects were not estradiol dose-dependent, as an intermediate dose of $0.0001 \mathrm{mg} / \mathrm{kg}$ estradiol increased responding for $0.03 \mathrm{mg} / \mathrm{kg} / \mathrm{inj}$. cocaine (Figure 2). In monkey Rh-RQ4000, estradiol tended to flatten the cocaine dose-effect curve and shift it to the right (Figure 3). In monkey $\mathrm{Rh}-\mathrm{CH} 165$, estradiol administration over a dose range of $0.00001-0.01 \mathrm{mg} / \mathrm{kg}$ did not alter the peak of the cocaine self-administration dose-effect curve (Figure 4). In monkey Rh-CH599, the peak of the cocaine dose-effect curve was at $0.03 \mathrm{mg} / \mathrm{kg} / \mathrm{inj}$. during saline treatment (Figure 5). $\mathrm{E}_{2} \beta$ over a dose range of $0.002-0.008 \mathrm{mg} / \mathrm{kg}$, i.m., had variable effects on the cocaine dose-effect curve. At $\mathrm{E}_{2} \beta$ doses of $0.002-0.008 \mathrm{mg} / \mathrm{kg}$, i.m., the peak of the cocaine dose-effect curve was shifted to the left. However, the overall curve was flattened during treatment with $0.004 \mathrm{mg} / \mathrm{kg}, \mathrm{E}_{2} \beta$ i.m., in comparison to the other conditions (Figure 5).

The number of cocaine injections earned during each quartile of the 2-h session is shown as bar graphs for each unit dose of cocaine. Extrapolating from the time course data shown in Figure 1, plasma estradiol levels should have been highest during the first and second quartile of the session. When saline or a low dose of cocaine was available for self-administration, monkeys often sampled during the first quartile of the session. In contrast, on the descending limb of the cocaine dose-effect curve, monkeys usually took a few cocaine injections in each component of the session. When the most reinforcing doses of cocaine were available, monkeys usually selfadministered cocaine in each of the four components of the session.

Plasma levels of $17 \beta$-estradiol after test sessions. Average levels of $17 \beta$-estradiol $(\mathrm{pg} / \mathrm{ml})$ measured at the end of the test session after determination of the cocaine dose-effect curves are shown in Figure 6. There was an $\mathrm{E}_{2} \beta$ dose-related increase in $17 \beta$-estradiol levels. Baseline $17 \beta$-estradiol levels during saline treatment were equivalent in the two gonadally intact monkeys $(29.5 \pm 3.8$ and $29.5 \pm 4.1 \mathrm{pg} / \mathrm{ml})$. Average $17 \beta$-estradiol levels after administration of saline and 0.00001 or $0.0001 \mathrm{mg} / \mathrm{kg} \mathrm{E}_{2} \beta$ did not differ significantly. After a higher dose of estradiol $(0.001 \mathrm{mg} / \mathrm{kg}$, i.m.), plasma estradiol levels averaged between 57 and $94 \mathrm{pg} / \mathrm{ml}$. Baseline estradiol levels in the two ovariectomized monkeys averaged $44.4 \pm 14.0$ and $18.2 \pm 0.9 \mathrm{pg} / \mathrm{ml}$.

\section{Estradiol Self-Administration}

Three monkeys were tested to determine if estradiol would maintain responding leading to its self-administration. Figure 7 shows that estradiol in cyclodextrin over a dose-range of $0.00001-0.1 \mathrm{mg} / \mathrm{kg}$, i.v., did not maintain 


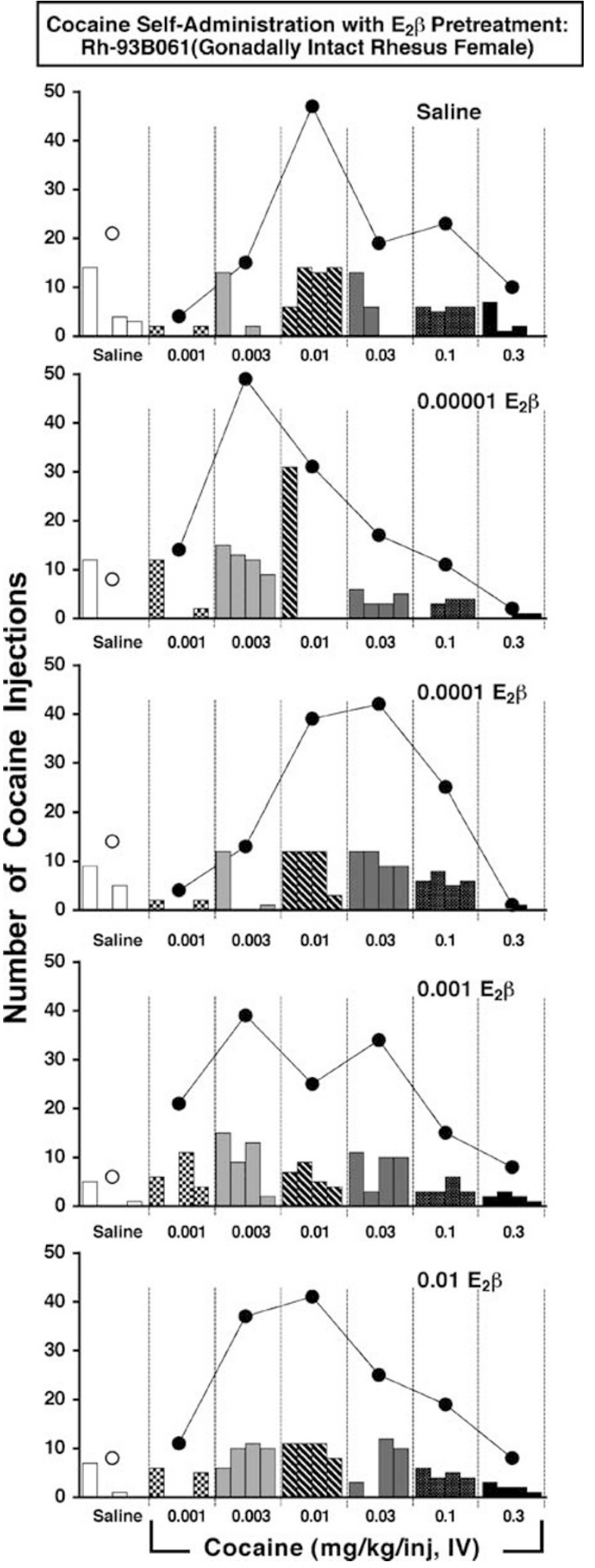

Figure 2 The effects of $E_{2} \beta$ on the cocaine self-administration doseeffect curve in an individual female rhesus monkey. The unit dose of cocaine $(\mathrm{mg} / \mathrm{kg} / \mathrm{inj}$.) is shown on the abscissae. The number of injections self-administered when only saline was available is shown above saline. The number of cocaine injections is shown on the left ordinate. The number of injections self-administered during each quartile of the session is shown as bars. Saline or the pretreatment dose of $E_{2} \beta$ is in the upper right of each row.
Cocaine Self-Administration with $\mathrm{E}_{2} \beta$ Pretreatment: Rh-RQ4000 (Gonadally Intact Rhesus Female)
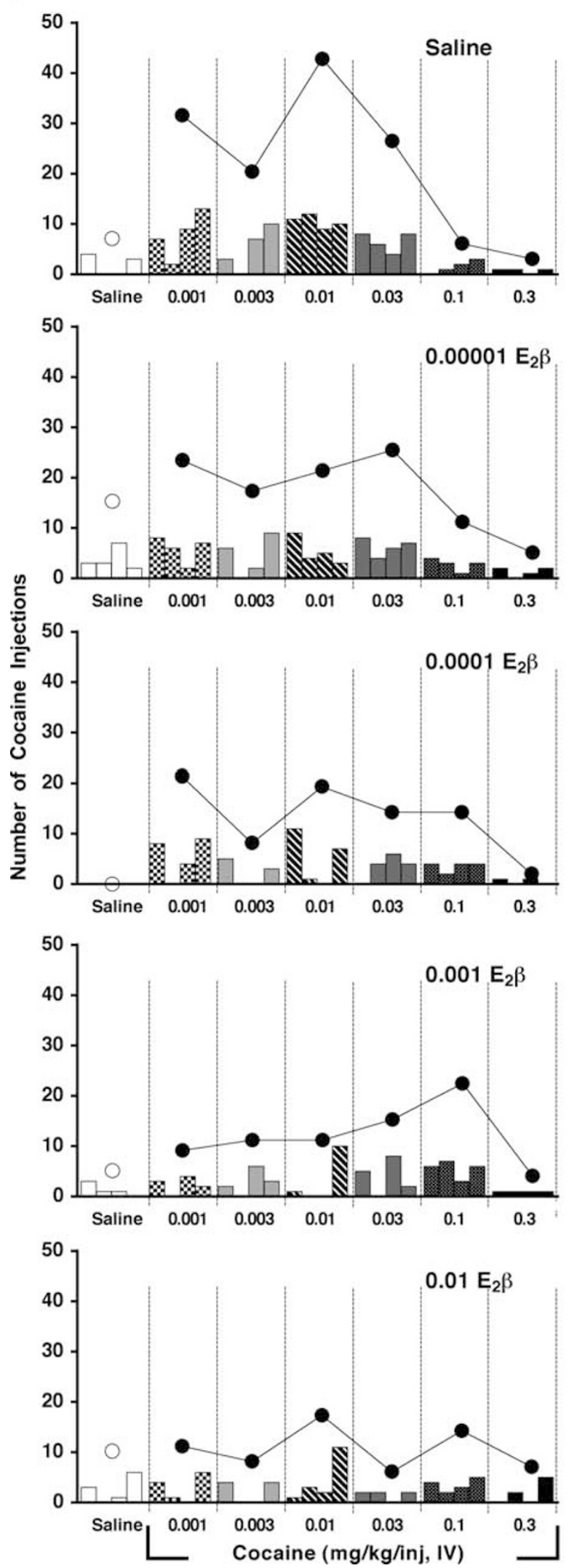

Figure 3 The effects of estradiol (E2 $\beta)$ on the cocaine dose-effect curve in an individual female rhesus monkey. See the legend of Figure 2 for details. 
Cocaine Self-Administration with $\mathrm{E}_{2} \beta$ Pretreatment: Rh-CH165 (OVX Rhesus Female)
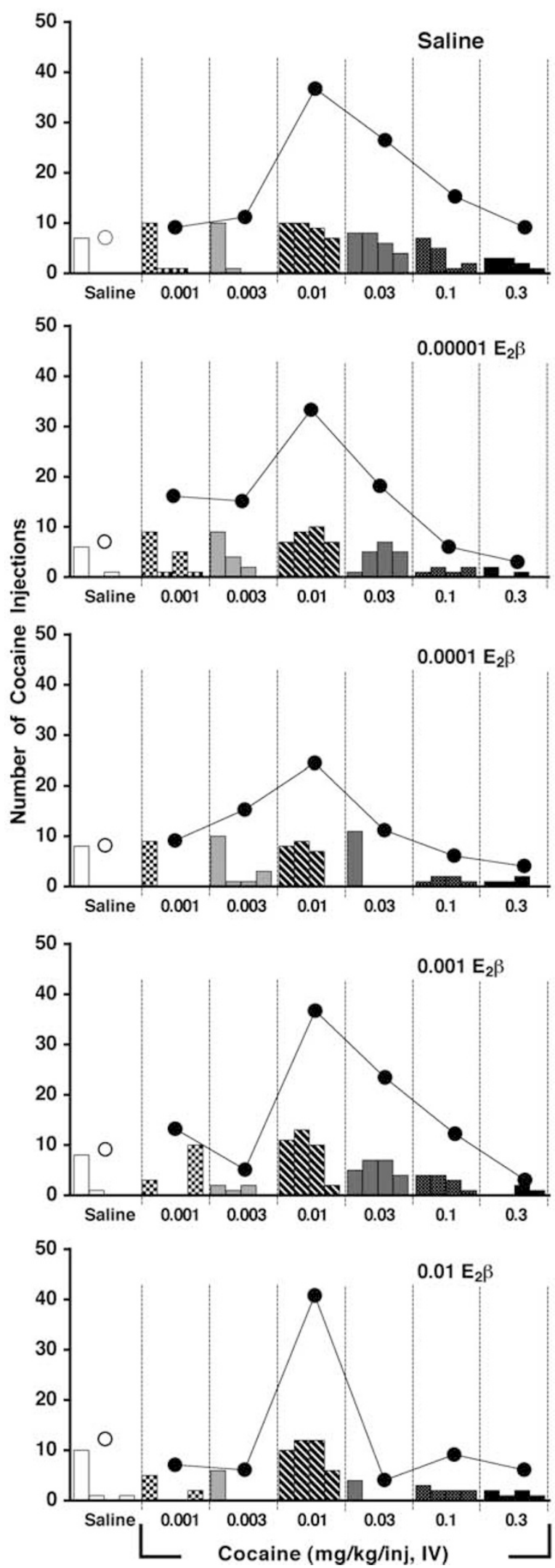

Figure 4 The effects of estradiol (E2 $\beta$ ) on the cocaine dose-effect curve in an individual female rhesus monkey. See the legend of Figure 2 for details.

\section{Cocaine Self-Administration with $\mathrm{E}_{2} \beta$ Pretreatment:} Rh-CH599 (OVX Rhesus Female)
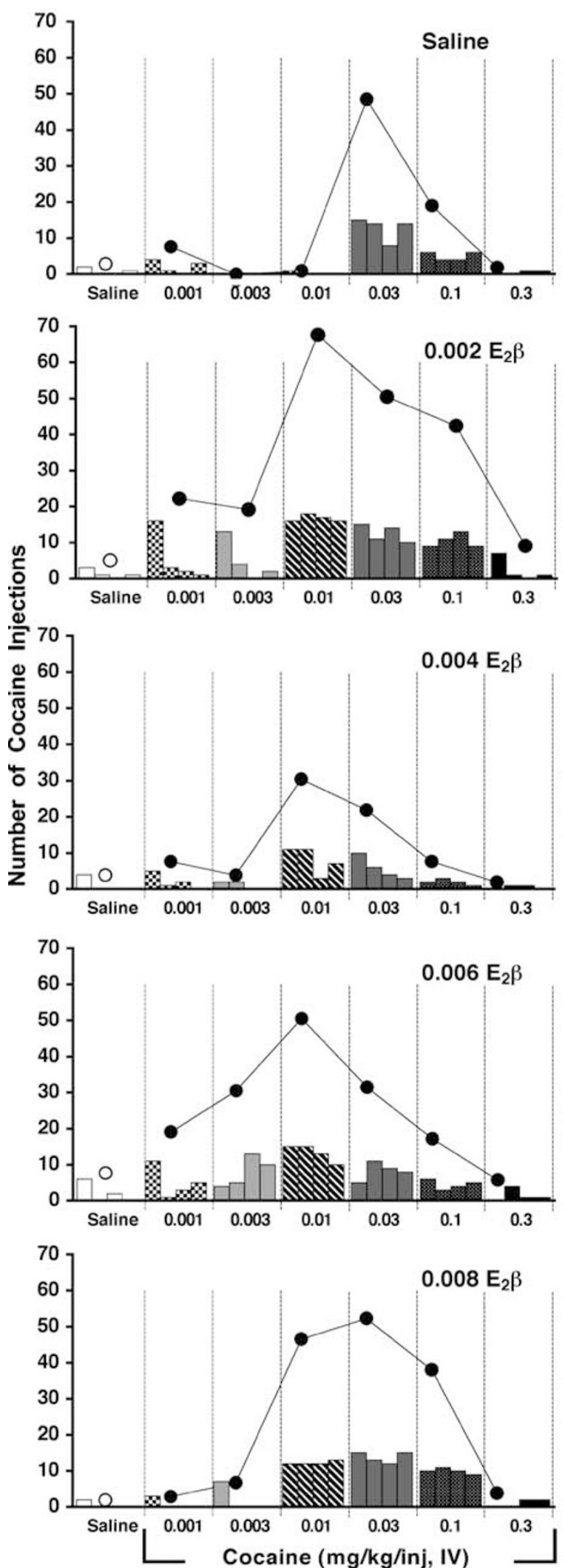

Figure 5 The effects of estradiol $(E 2 \beta)$ on the cocaine dose-effect curve in an individual female rhesus monkey. See the legend of Figure 2 for details. 


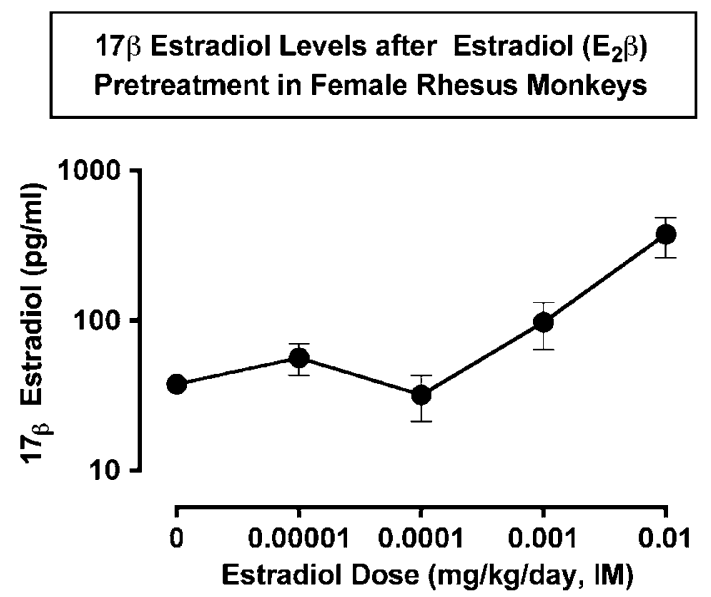

Figure 6 Average plasma estradiol levels after estradiol pretreatment in female rhesus monkeys. Abscissa: dose of estradiol ( $\mathrm{mg} / \mathrm{kg} /$ day, i.m.). Ordinate: plasma levels of $17 \beta$-estradiol $(\mathrm{pg} / \mathrm{ml})$. Each data point is the average of three female rhesus monkeys.

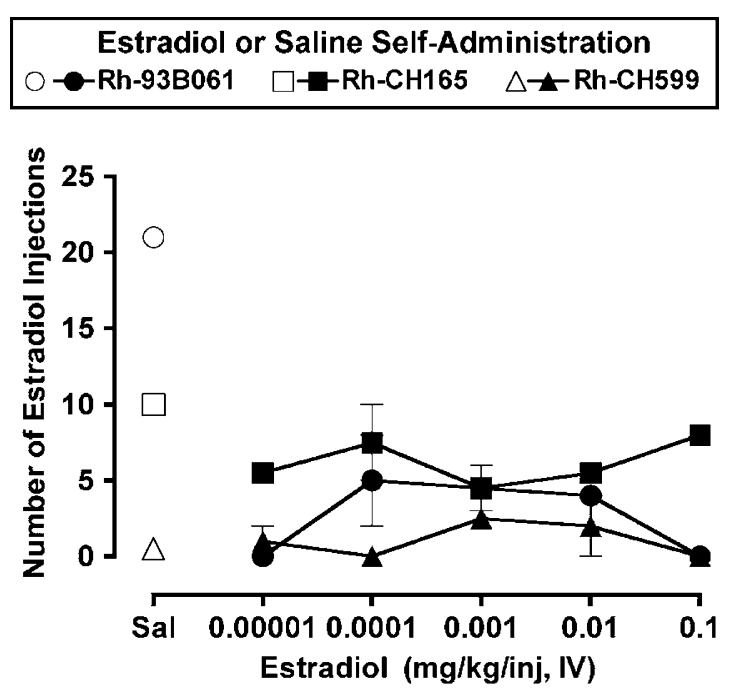

Figure 7 E2 $\beta$ self-administration in individual female rhesus monkeys. Abscissae: dose of $E_{2} \beta\left(\mathrm{mg} / \mathrm{kg}\right.$, i.v.). Ordinate: the number of saline or $E_{2} \beta$ injections self-administered during a 2-h session. Each data point is the average of two determinations except the saline point for Rh-93B06I, which is a single determination.

responding above saline self-administration levels. Fewer than 10 injections per $2 \mathrm{~h}$ session were consistently observed at all estradiol doses.

\section{Cocaine Discrimination: $\mathrm{E}_{2} \boldsymbol{\beta}$ Substitution Studies}

Three monkeys were tested in substitution studies and in pretreatment studies with $\mathrm{E}_{2} \beta$ in cyclodextrin vehicle (Figure 8 and Table 1). On training days throughout the course of these studies, monkeys responded exclusively on the saline-appropriate key during saline training cycles and almost exclusively on the cocaine-appropriate key during cocaine training cycles (mean \% cocaine-appropriate responding \pm SEM $=99.68 \pm 0.16 \%)$. Mean response rates \pm SEM were $0.76 \pm 0.13$ responses/s during saline training
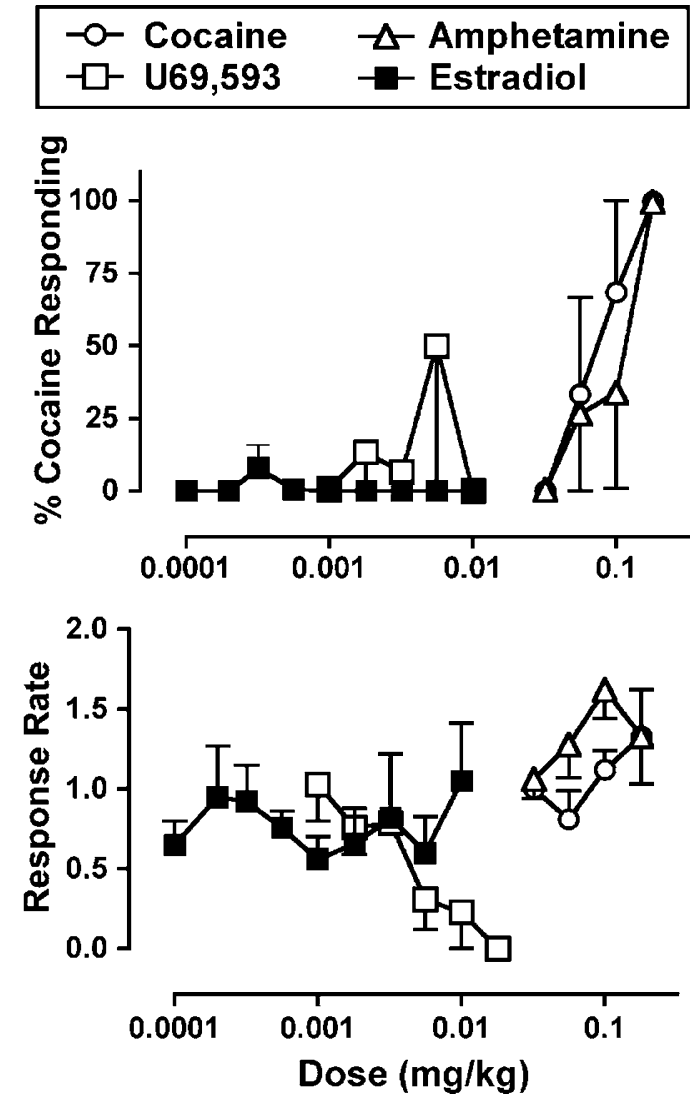

Figure 8 Effects of cocaine, amphetamine, U69,593, and estradiol $\left(E_{2} \beta\right)$ administered alone in female rhesus monkeys trained to discriminate $0.18 \mathrm{mg} / \mathrm{kg}$ cocaine from saline. Abscissae: dose in $\mathrm{mg} / \mathrm{kg}$ (log scale). Ordinates: (top panels) percent cocaine-appropriate responding; (bottom panels) response rate in responses/s. All dose-effect curves show mean data \pm SEM from three monkeys.

Table I $\mathrm{ED}_{50}$ Values in $\mathrm{mg} / \mathrm{kg}(95 \% \mathrm{CL})$ for Cocaine Administered Alone or 30 min after Pretreatment with $E_{2} \beta$ in a Cyclodextrin Vehicle

\begin{tabular}{lc}
\hline Treatment & ED50 (95\% CL) \\
\hline Cocaine alone & $0.074(0.039-0.14)$ \\
+0.000 I estradiol & $0.068(0.032-0.14)$ \\
+0.00 I estradiol & $0.070(0.034-0.14)$ \\
+0.0 I estradiol & $0.10(0.10-0.10)$ \\
\hline
\end{tabular}

cycles and $1.42 \pm 0.11$ responses/s during cocaine training cycles. Thus, there was a tendency for the training dose of cocaine to increase response rates relative to saline treatment.

Figure 8 shows the effects of substitution tests. Cocaine produced a dose-dependent increase in cocaine-appropriate responding, and the control $\mathrm{ED}_{50}$ value is shown in Table 1 . $d$-Amphetamine also produced a dose-dependent and complete substitution for the cocaine training stimulus with a potency similar to that of cocaine $\left(\mathrm{ED}_{50}(95 \%\right.$ $\mathrm{CL})=0.10 \quad(0.60-0.17) \mathrm{mg} / \mathrm{kg})$. In contrast, the kappa opioid receptor agonist U69,593 produced primarily 
saline-appropriate responding up to doses that eliminated responding. In the only exception to this finding, U69,593 produced $100 \%$ cocaine-appropriate responding in one monkey at a high dose of $0.0056 \mathrm{mg} / \mathrm{kg}$ that also reduced response rates; however, only saline-appropriate responding was observed during the second determination of the U69,593 dose-effect curve in this monkey. Estradiol had little effect on either cocaine-appropriate responding or response rates across the dose ranges tested.

\section{$\mathrm{E}_{2} \beta$ Effects on Cocaine Discrimination Dose-Effect Curves}

Figure 9 shows the effects of pretreatment with $\mathrm{E}_{2} \beta$ dissolved in cyclodextrin or sesame oil vehicle on cocaine discrimination. Cocaine discrimination $\mathrm{ED}_{50}$ values are shown in Table $1 . \mathrm{E}_{2} \beta$ did not significantly alter the discriminative stimulus effects of cocaine in either procedure. The lower panels of figures show the rate-altering effects of cocaine administered alone or after pretreatment with $\mathrm{E}_{2} \beta$. As noted above, cocaine increased response rates slightly at the training dose of $0.18 \mathrm{mg} / \mathrm{kg}$, and a higher dose of $0.56 \mathrm{mg} / \mathrm{kg}$ tended to decrease response rates (decreases observed in two of three monkeys). Pretreatment with $\mathrm{E}_{2} \beta$ in cyclodextrin had little effect on the overall pattern of cocaine's rate-altering effects.

Four monkeys were tested in pretreatment studies with $\mathrm{E}_{2} \beta$ in a sesame oil vehicle. On training days throughout the course of these studies, monkeys responded almost exclusively on the saline-appropriate key during saline training cycles (mean \% saline-appropriate responding \pm SEM $=99.97 \pm 0.03 \%)$ and exclusively on the cocaineappropriate key during cocaine training cycles. Mean response rates \pm SEM were $1.83 \pm 0.38$ responses/s during saline training cycles and $2.16 \pm 0.18$ responses/s during cocaine training cycles. Pretreatment with the highest dose of $\mathrm{E}_{2} \beta$ dissolved in sesame oil did not significantly alter the discriminative stimulus effects of cocaine on either the first or second day of hormone treatment. Cocaine discrimination $\mathrm{ED}_{50}$ values for tests with vehicle and all $\mathrm{E}_{2} \beta$ doses are shown in Table 2.

\section{DISCUSSION}

Estradiol had variable effects on the cocaine self-administration dose-effect curves in female rhesus monkeys. Although low doses of estradiol shifted the peak of the

\section{Effects of Estradiol $\left(E_{2} \beta\right)$ Pretreatment on Cocaine Discrimination}

Estradiol in Cyclodextrin

-O-Cocaine Alone

$\longrightarrow+0.0001$ Estradiol

-+0.001 Estradiol

+0.01 Estradiol
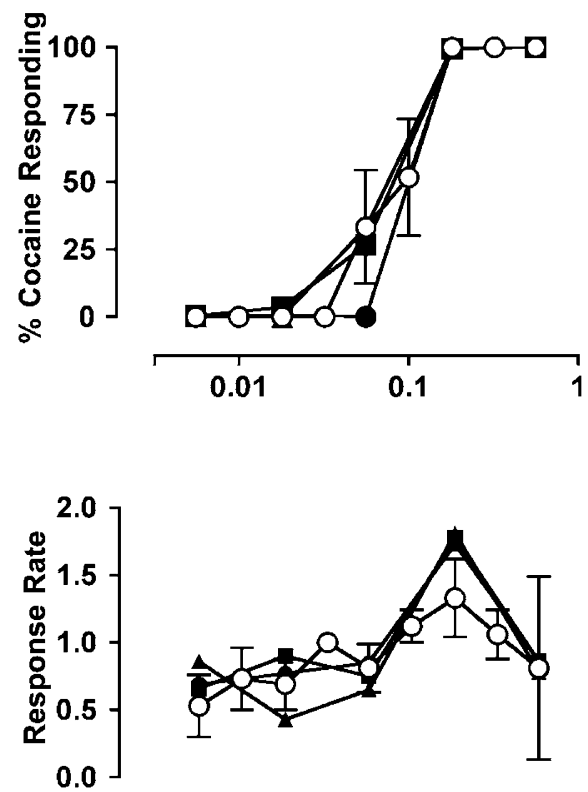

0.01
0.1

\section{Dose}

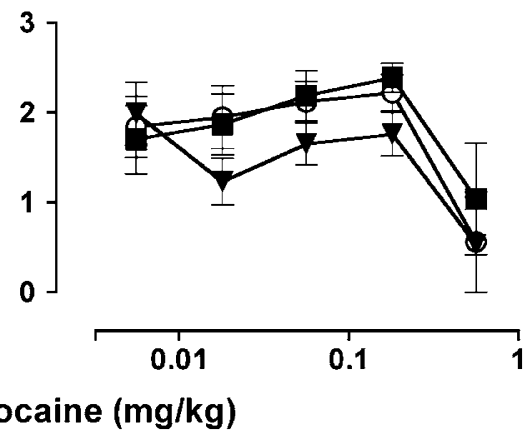

Figure 9 Effects of estradiol in cyclodextrin or sesame oil vehicle on the discriminative stimulus and rate-altering effects of cocaine. Abscissae: dose cocaine in $\mathrm{mg} / \mathrm{kg}$. Ordinates: percent cocaine-appropriate responding (top) or response rate in responses/s (bottom). The highest dose of estradiol $(0.01 \mathrm{mg} / \mathrm{kg})$ in sesame oil was administered for 2 days. Each point shows mean data \pm SEM in three or four monkeys. 
Table $2 \mathrm{ED}_{50}$ Values in $\mathrm{mg} / \mathrm{kg}(95 \% \mathrm{CL})$ for Cocaine Administered Alone or after I or 2 Days of Treatment with Sesame Oil Vehicle and $E_{2} \beta$ in a Sesame Oil Vehicle

\begin{tabular}{lllr}
\hline Treatment & Control & Day I & Day 2 \\
\hline Sesame oil vehicle & $0.075(0.043-0.13)$ & $0.057(0.031-0.11)$ & $0.057(0.030-0.11)$ \\
+0.000 I estradiol & $0.075(0.043-0.13)$ & $0.041(0.025-0.067)$ & $0.056(0.029-0.11)$ \\
+0.00 I estradiol & $0.049(0.030-0.082)$ & $0.077(0.046-0.13)$ & $0.075(0.043-0.13)$ \\
+0.01 estradiol & $0.057(0.030-0.11)$ & $0.073(0.042-0.12)$ & $0.057(0.030-0.11)$ \\
\hline
\end{tabular}

cocaine dose-effect curve to the left in some monkeys, these effects were not estradiol dose-dependent. The highest dose of estradiol studied did not alter the cocaine dose-effect curve appreciably from control conditions. Findings in the present study are consistent with clinical studies in which estradiol was administered to follicular phase women before exposure to $d$-amphetamine (Justice and de Wit, 2000b). Estradiol levels, 10 times the usual follicular phase levels, did not significantly enhance most positive subjective responses to $d$-amphetamine (Justice and de Wit, 2000b). Women studied at the early follicular phase of the menstrual cycle, when estradiol levels are low, and at the late follicular phase, when estradiol levels are high, also did not respond differently to $d$-amphetamine (Justice and de Wit, 2000a). Similarly, cynomolgus female monkeys did not alter patterns of cocaine self-administration as a function of menstrual cycle phase when reinforcing unit doses of cocaine were available $(0.01$ and $0.032 \mathrm{mg} / \mathrm{kg} / \mathrm{inj}$.) (Mello et al, 2007). Progressive ratio breakpoints were stable across 34 menstrual cycles in which ovulation was verified by a mid-luteal phase elevation of progesterone (Mello et al, 2007). However, when a low dose of cocaine $(0.0032 \mathrm{mg} / \mathrm{kg} /$ inj.) was available that did not maintain reliable or robust cocaine self-administration, progressive ratio breakpoints were significantly higher during the early- and midfollicular phase than during the late luteal phase of 10 ovulatory menstrual cycles (Mello et al, 2007).

These findings in the rhesus monkeys are not consistent with many studies in rodents where estradiol administration (Hu et al, 2004; Jackson et al, 2006; Lynch et al, 2001) and the estrus phase of the estrous cycle are usually associated with increases in cocaine self-administration (Hecht et al, 1999; Lynch et al, 2000, 2001; Roberts et al, 1989). Several procedural differences may account, in part, for these discrepant findings. First, multiple doses of exogenous estradiol were administered to rhesus monkeys in the present study, whereas in rats, the effects of spontaneous fluctuations in endogenous estradiol across the estrous cycle are often studied. Usually gonadal steroid levels in rats are not measured to verify estrous cycle phase. However, it is unlikely that differences in relative estradiol levels account for the different findings in rats and monkeys. The lowest doses of $\mathrm{E}_{2} \beta$ produced physiological levels of estradiol consistent with the follicular phase of the rhesus menstrual cycle, and higher doses of estradiol were in the normal range for the periovulatory phase (Hotchkiss and Knobil, 1994; Knobil and Hotchkiss, 1988; Mello et al, 1997). A second procedural difference is that in the present study with rhesus monkeys, complete cocaine dose-effect curves were determined during estradiol treatment, whereas in rats, usually only one or two cocaine doses were examined at each phase of the estrous cycle. When complete cocaine dose-effect curves were determined in ovariectomized female rats, there was no significant effect of estradiol administration on cocaine self-administration (Caine et al, 2004). Finally, the response requirement for cocaine was an FR 30 in rhesus monkeys, and usually an FR 1 or an FR 5 schedule is used in rodents.

Baseline cocaine dose-effect curves and responses to exogenous estradiol were very similar in gonadally intact and ovariectomized female rhesus monkeys. These data are consistent with some but not all previous studies in rodents. For example, when drug-naïve ovariectomized rats were given access to high unit doses of cocaine $(1.0-2.5 \mathrm{mg} / \mathrm{kg} /$ inj.), acquisition of cocaine self-administration did not differ significantly from gonadally intact females (Caine et al, 2004; Grimm and See, 1997) or from ovariectomized females with estrogen replacement (Lynch and Taylor, 2005). Moreover, there were no differences in the shape and position of the cocaine dose-effect curve $(0.032-3.2 \mathrm{mg} / \mathrm{kg} /$ inj.) determined before and after ovariectomy, or in ovariectomized females before and after estradiol replacement (Caine et al, 2004). In other studies, estrogen replacement enhanced cocaine self-administration in ovariectomized rats ( $\mathrm{Hu}$ et al, 2004). However, when high unit doses of cocaine were available, there were no differences in cocaine self-administration between ovariectomized rats with and without estrogen replacement (Hu et al, 2004).

There is considerable evidence that both estradiol and cocaine increase extracellular dopamine levels in rodents (Becker, 1999; Becker et al, 2001; Di Chiara, 1995; Hemby et al, 1997). However, estradiol did not maintain selfadministration above saline levels in these cocaine-trained female rhesus monkeys. We were unable to locate previous preclinical studies of estradiol self-administration. However, the gonadal steroid hormone, testosterone, has been shown to maintain i.v. self-administration in male rats and oral and intracerebroventricular self-administration in hamsters (Johnson and Wood, 2001; Wood et al, 2004).

In drug discrimination studies, estradiol also did not produce cocaine-appropriate responding. The discriminative stimulus and rate-altering effects of cocaine were not significantly altered by acute pretreatment with estradiol in cyclodextrin or by 2 days of treatment with estradiol in a sesame oil vehicle. These data suggest that neither the rapid non-genomic nor the slow genomic effects of estradiol significantly influenced the discriminative stimulus effects of cocaine across the dose range studied. These findings 
cannot be attributed to a lack of robust cocaine discrimination, because monkeys discriminated cocaine from saline with almost $99 \%$ accuracy. Moreover, cocaine $(0.18 \mathrm{mg} / \mathrm{kg})$ appeared to function as a pharmacologically selective discriminative stimulus, because when $d$-amphetamine was substituted for cocaine, it produced dose-related cocaine-appropriate responding, whereas the kappa opioid U69,593 did not. These data suggest that acute administration of estradiol in a cyclodextrin vehicle (which promotes rapid distribution) did not share reinforcing or discriminative stimulus effects with cocaine. Gonadal steroid hormones have been shown to serve as discriminative stimuli under some behavioral conditions in rodents (De Beun, 1999).

One limitation of the present report is that fewer monkeys were used in each component study than in many clinical studies and preclinical studies in rats. However, a strength of the study is that each monkey was studied as her own control under saline and four estradiol pretreatment doses in cocaine self-administration studies, and saline and three estradiol pretreatment doses in drug discrimination studies. Moreover, cocaine self-administration dose-effect curves (0.001-0.3 mg/kg/inj.) and cocaine discrimination doseeffect curves $(0.01-1.0 \mathrm{mg} / \mathrm{kg}$, i.m.) were determined in each estradiol pretreatment condition. In addition, in estradiol self-administration studies, dose-effect curves (0.00001$0.10 \mathrm{mg} / \mathrm{kg}$, i.v.) were determined in the same monkeys. An own-control design with repeated measures across conditions reduces variability and increases statistical power in comparison to group designs where different subjects are used in each condition (Cohen, 1988; Ellis, 1999).

In summary, although estradiol appears to enhance the reinforcing effects of cocaine in rodents under some conditions, there were no robust dose-dependent effects of estradiol on cocaine self-administration or cocaine discrimination in female rhesus monkeys under the conditions of the present study. Normally cycling cynomolgus females also did not alter patterns of cocaine self-administration as a function of menstrual cycle phase at unit doses on the ascending limb of the cocaine dose-effect curve (Mello et al, 2007). Findings in the present study are consistent with clinical studies in which estradiol failed to enhance responses to $d$-amphetamine (Justice and de Wit, 2000a,b). When cocaine unit doses that maintained consistent self-administration were available in rodents, the effects of estradiol often were not significant (Caine et al, 2004; Grimm and See, 1997; Lynch and Taylor, 2005). Taken together, these findings suggest that the effects of estradiol on the abuse-related effects of cocaine are subtle at best. In women, the subjective effects of cocaine and $d$-amphetamine are usually greatest during the follicular phase of the menstrual cycle when both estradiol and progesterone levels are low (Evans et al, 2002; Justice and de Wit, 1999; Sofuoglu et al, 1999; White et al, 2002). Progesterone reduced the positive effects of smoked and i.v. cocaine in women (Evans and Foltin, 2006; Sofuoglu et al, 2002, 2004) and i.v. cocaine self-administration in rodents (Feltenstein and See, 2007, in press; Jackson et al, 2006). Much remains to be learned about the complex interactions between the gonadal steroid hormones and the abuse-related effects of cocaine (Mello and Mendelson, 2002).

\section{ACKNOWLEDGEMENTS}

This research was supported by R01-DA14670, P01DA14528, K05-DA00101, and K05-DA00064 from the National Institute on Drug Abuse, NIH. We thank Peter A Fivel, Sam McWilliams, Ashley Bear, Melissa Timm, and Nadia Tikhomirova for their excellent technical assistance and Dr PK Sehgal for veterinary assistance.

\section{DISCLOSURE/CONFLICT OF INTEREST}

None.

\section{REFERENCES}

Becker JB (1999). Gender differences in dopaminergic function in striatum and nucleus accumbens. Pharmacol Biochem Behav 64: 803-812.

Becker JB, Breedlove SM, Crews D, McCarthy MM (eds) (2002). Behavioral Endocrinology, 2nd edn. A Bradford Book, The MIT Press: Cambridge, MA, 775 pp.

Becker JB, Molenda H, Hummer DL (2001). Gender differences in the behavioral responses to cocaine and amphetamine. Implications for mechanisms mediating gender differences in drug abuse. Ann NY Acad Sci 937: 172-187.

Caine SB, Bowen CA, Yu G, Zuzga D, Negus SS, Mello NK (2004). Effect of gonadectomy and gonadal hormone replacement on cocaine self-administration in female and male rats. Neuropsychopharmacology 29: 929-942.

Carroll ME, Lynch WJ, Roth ME, Morgan AD, Cosgrove KP (2004). Sex and estrogen influence drug abuse. Trends Pharmacol Sci 25: 273-279.

Clark UH, Mani SK (1994). Actions of ovarian steroid hormones. In: Knobil E, Neill JD (eds). The Physiology of Reproduction, 2nd edn. Raven Press Ltd: New York. pp 1011-1059.

Cohen J (1988). Statistical Power Analyses for the Behavioral Science, 3rd edn. Academic Press: New York.

Collins SL, Evans SM, Foltin RW, Haney M (2007). Intranasal cocaine in humans; effects of sex and menstrual cycle. Pharmacol Biochem Behav 86: 117-124.

De Beun R (1999). Hormones of the hypothalamo-pituitarygonadal axis in drug discrimination learning. Pharmacol Biochem Behav 64: 311-317.

Di Chiara G (1995). The role of dopamine in drug abuse viewed from the perspective of its role in motivation. Drug Alcohol Depend 38: 95-137.

Dierschke DJ, Yamaji T, Karsch FJ, Weick RF, Weiss G, Knobil E (1973). Blockade by progesterone of estrogen-induced LH and FSH release in the rhesus monkey. Endocrinology 92: 1496-1501.

Ellis MV (1999). Repeated measures designs. Couns Psychol 27: 552-578.

Evans SM, Foltin RW (2006). Exogenous progesterone attenuates the subjective effects of smoked cocaine in women, but not in men. Neuropsychopharmacology 31: 659-674.

Evans SM, Haney M, Foltin RW (2002). The effects of smoked cocaine during the follicular and luteal phases of the menstrual cycle in women. Psychopharmacology 159: 397-406.

Falkenstein E, Tillmann H-C, Christ M, Feuring M, Wehling M (2000). Multiple actions of steroid hormones - a focus on rapid, nongenomic effects. Pharmcol Rev 52: 513-555.

Feltenstein MW, See RE (2007). Plasma progesterone levels and cocaine-seeking in freely cycling female rats across the estrous cycle. Drug Alcohol Depend (in press).

Festa ED, Quinones-Jenab V (2004). Gonadal hormones provide the biological basis for sex differences in behavioral responses to cocaine. Horm Behav 46: 509-519. 
Freeman ME (1994). The neuroendocrine control of the ovarian cycle of the rat. In: Knobil E, Neill JD (eds). The Physiology of Reproduction, 2nd edn. Raven Press: New York. pp 613-658.

Grimm JW, See RE (1997). Cocaine self-administration in ovariectomized rats is predicted by response to novelty, attenuated by 17- $\beta$ estradiol, and associated with abnormal vaginal cytology. Physiol Behav 61: 755-761.

Hecht GS, Spear NE, Spear LP (1999). Changes in progressive ratio responding for intravenous cocaine throughout the reproductive process in female rats. Dev Psychobiol 35: 136-145.

Hemby SE, Co C, Koves TR, Smith JE, Dworkin SI (1997). Differences in extracelluar dopamine concentrations in the nucleus accumbens during response-dependent and responseindependent cocaine administration in the rat. Psychopharmacol 133: $7-16$

Hotchkiss J, Knobil E (1994). The menstrual cycle and its neuroendocrine control. In: Knobil E, Neill JD (eds). The Physiology of Reproduction, Vol. 2, 2nd edn. Raven Press: New York. pp 711-749.

$\mathrm{Hu}$ M, Crombag HS, Robinson TE, Becker JB (2004). Biological basis of sex differences in the propensity to self-administer cocaine. Neuropsychopharmacology 29: 81-85.

Jackson LR, Robinson TE, Becker JB (2006). Sex differences and hormonal influences on acquisition of cocaine self-administration in rats. Neuropsychopharmacology 31: 129-138.

Johnson LR, Wood RI (2001). Anabolic steroid abuse: studies in oral testosterone self-administration. Neuroendocrinology 73: 285-292.

Justice AJH, de Wit $\mathrm{H}$ (1999). Acute effects of $d$-amphetamine during the follicular and luteal phases of the menstrual cycle in women. Psychopharmacology 145: 67-75.

Justice AJ, de Wit H (2000a). Acute effects of $d$-amphetamine during the early and late follicular phases of the menstrual cycle in women. Pharmacol Biochem Behav 66: 509-515.

Justice AJ, de Wit H (2000b). Acute effects of estradiol pretreatment on the response to $d$-amphetamine in women. Neuroendocrinology 71: 51-59.

Knobil E (1980). The neuroendocrine control of the menstrual cycle. Recent Prog Horm Res 36: 53-88.

Knobil E, Hotchkiss J (1988). The menstrual cycle and its neuroendocrine control. In: Knobil E, Neill J, Ewing LL, Greenwald GS, Markert CL, Pfaff DW (eds). The Physiology of Reproduction. Raven Press: New York. pp 1971-1994.

Kuhar MJ, Ritz MC, Boja JW (1991). The dopamine hypothesis of the reinforcing properties of cocaine. Trends Nerosci 14: 299-302.

Line SW (1987). Environmental enrichment for laboratory primates. J Am Vet Med Assoc 90: 854-859.

Lukas SE, Sholar M, Lundahl LH, Lamas X, Kouri E, Wines JD et al (1996). Sex differences in plasma cocaine levels and subjective effects after acute cocaine administration in human volunteers. Psychopharmacology 125: 346-354.

Lynch WJ, Arizzi MN, Carroll ME (2000). Effects of sex and the estrous cycle on regulation of intravenously self-administered cocaine in rats. Psychopharmacology 152: 132-139.

Lynch WJ, Roth ME, Carroll ME (2002). Biological basis of sex differences in drug abuse: preclinical and clinical studies. Psychopharmacology 164: 121-137.

Lynch WJ, Roth ME, Mickelberg JL, Carroll ME (2001). Role of estrogen in the acquisition of intravenously self-administered cocaine in female rats. Pharmacol Biochem Behav 68: 641-646.

Lynch WJ, Taylor JR (2005). Decreased motivation following cocaine self-administration under extended access conditions: effects of sex and ovarian hormones. Neuropsychopharmacology 30: $927-935$

Mello NK, Knudson IM, Mendelson JH (2007). Sex and menstrual cycle effects on progressive ratio measures of cocaine self-administration in cynomolgus monkeys. Neuropsycho- pharmacology (advance online publication, 24 January 2007; doi:10.1038/sj.npp.1301314).

Mello NK, Mendelson JH (2002). Cocaine, hormones and behavior: clinical and preclinical studies. In: Pfaff DW, Arnold AP, Etgen AM, Fahrbach SE, Rubin RT (eds). Hormones, Brain and Behavior, Vol. 5. Academic Press: New York. pp 665-745.

Mello NK, Mendelson JH, Kelly M, Bowen CA (2000). The effects of cocaine on basal and human chorionic gonadotropinstimulated ovarian steroid hormones in female rhesus monkeys. J Pharmacol Exp Ther 294: 1137-1145.

Mello NK, Mendelson JH, Kelly M, Diaz-Migoyo N, Sholar JW (1997). The effects of chronic cocaine self-administration on the menstrual cycle in rhesus monkeys. J Pharmacol Exp Ther 281: 70-83.

Mello NK, Mendelson JH, Negus SS, Kelly M (2004b). Ovarian steroid hormone modulation of the acute effects of cocaine on luteinizing hormone and prolactin levels in ovariectomized rhesus monkeys. J Pharmacol Exp Ther 308: 156-167.

Mello NK, Mendelson JH, Negus SS, Kelly M, Knudson I, Roth ME (2004a). The effects of cocaine on gonadal steroid hormones and LH in male and female rhesus monkeys. Neuropsychopharmacology 29: 2024-2034.

Mendelson JH, Mello NK, Sholar MB, Siegel AJ, Kaufman MJ, Levin JM et al (1999). Cocaine pharmacokinetics in men and in women during the follicular and luteal phase of the menstrual cycle. Neuropsychopharmacology 21: 294-303.

Moore FL, Evans SJ (1999). Steroid hormones use non-genomic mechanisms to control brain functions and behaviors: a review of evidence. Brain Behav Evol 54: 41-50.

Munro CA, McCaul ME, Wong DF, Oswald LM, Zhou Y, Brasic J et al (2006). Sex differences in striatal dopamine release in healthy adults. Biol Psychiatry 59: 966-974.

Roberts DSC, Bennett SA, Vickers GJ (1989). The estrous cycle affects cocaine self-administration on a progressive ratio schedule in rats. Psychopharmacology 98: 408-411.

Sofuoglu M, Babb DA, Hatsukami DK (2002). Effects of progesterone treatment on smoked cocaine response in women. Pharmacol Biochem Behav 72: 431-435.

Sofuoglu M, Dudish-Poulsen S, Nelson D, Pentel PR, Hatsukami DK (1999). Sex and menstrual cycle differences in the subjective effects from smoked cocaine in humans. Exp Clin Psychopharmacol 7: 274-283.

Sofuoglu M, Mitchell E, Kosten TR (2004). Effects of progesterone treatment on cocaine responses in male and female cocaine users. Pharmacol Biochem Behav 78: 699-705.

Van Vugt DA, Heisler LE, Reid RL (1992). Progesterone inhibits the estrogen-induced gonadotropin surge in the rhesus monkey independent of endogenous opiates. J Clin Endocrinol Metab 74: $1312-1319$

Vasudevan N, Pfaff DW (2007). Membrane-initiated actions of estrogens in neuroendocrinology: emerging principles. Endocr Rev 28: 1-19.

White TL, Justice AJ, de Wit H (2002). Differential subjective effects of $d$-amphetamine by gender, hormone levels and menstrual cycle phase. Pharmacol Biochem Behav 73: 729-741.

Wildt L, Hutchison JS, Marshall G, Pohl CR, Knobil E (1981). On the site of action of progesterone in the blockade of the estradiol-induced gonadotropin discharge in the rhesus monkey. Endocrinology 109: 1293-1294.

Wong M, Thompson TL, Moss RL (1996). Nongenomic actions of estrogen in the brain: physiological significance and cellular mechanisms. Crit Rev Neurobiol 10: 189-203.

Wood RI, Johnson LR, Chu L, Schad C, Self DW (2004). Testosterone reinforcement: intravenous and intracerebroventricular self-administration in male rats and hamsters. Psychopharmacology 171: 298-305.

Woolverton WL, Johnson KM (1992). Neurobiology of cocaine abuse. Trends Pharmacol Sci 13: 193-200. 